\title{
Identifying Direct Electrical Energy Demand in Wire-Cut EDM
}

\author{
ANIS FATIMA*, AND SYED AMIR IQBAL* \\ RECEIVED ON 27.11.2018 ACCEPTED ON 19.02.2019 \\ ABSTRACT
}

\begin{abstract}
Non-traditional machining processes are popular for generating complex features on the work piece. With advances in material engineering, new ways of cutting technologies has been emerged. However, EDM (Electric Discharge Machining) has gained recognition for producing extraordinary surface finished, intricate part geometries with accuracy and its ability to cut through difficult to machined materials. However, like every product cycle, manufacturing processes also require energy to convert raw materials into finished product. In manufacturing operations, energy input gives carbon footprints which have an effect on our environment. It is observed that reducing energy consumption is becoming the main concern of manufacturers because of enforcing environmental laws and due to the economics of the processing. It is argued that world's $70 \%$ of energy consumption is consumed by manufacturing sector. The aim of the work was to identify direct energy demands in wire cut EDM. The variability in energy demand was explored by operating wire cut EDM at no-load and loaded conditions.Stainless steel S304 was used as a work piece. Experiments were performed on three different wire-cut EDM.Molybdenum wire, brass wire andcopper wire were used as an electrode wire and distilled water was used as a working fluid. During the experiment, electrical current was measured and the variation of power requirement was evaluated. Power required by different features of EDM was compared with the existing energy models and factors were identified that consume most of the electrical energy. Further, a comparison is made between traditional and non-traditional machining processes. This contribution will help to assess energy efficiency of EDM technology and identify priority areas for improvements. This work is also significant for machine tool designers for optimum utilization of energy,reduced environmental impact and reduced production cost of their machine tool.
\end{abstract}

Key Words: Non-Traditional Process, Energy, Electric Discharge Machining.

\section{INTRODUCTION}

$\mathrm{E}$

nergy is the basic source of life and every product cycle requires energy consumption. Demand of energy is increasing day by day and it is expected to continue in future. A rapid increase in the consumption of products and services has increased environmental pollution that has become the main threat to human and society. Most of the pollution is experienced due to the consumption of energy and emission of carbon foot prints. On record, major portion of energy is consumed in manufacturing businesses. Hence, manufacturing business plays a vital role in climate change. Manufacturing process is the process of converting raw 
materials into finished products. For this transformation, it requires several intakes and produces waste. These wastes are found either in the form of material or in the form of energy. Due to the impacts of manufacturing processes on environment, it has become the main concern of manufacturers to perform operations which affect less on environment [1-2]. Manufacturers are trying their best to prevent pollution which is also helpful in reducing waste. Reducing the production of hazardous waste is also reducing the issues regarding health and environment.United States : OTA(Office on Technology Assessments) determines five large approaches towards pollution prevention [3]: In-process recycling, process technology and equipment, plant operations, process input and end products.

For developing countries like Pakistan that are facing uphill tasks to meet the ever increasing demand of energy, efficient resource utilization is the key for sustainable development [4]. A study [5] published on action to reduce energy crises discussed the policy frame work for energy conversation. However, it only discusses the management issues on energy conversation based on short term plan. Sustainable development of any country depends on how well its natural resources are consumed without depleting it for future generations. Among many one way to do this is to reduce pollution. Reducing pollution is actually reducing waste which can only be possible by reducing source. Two main source inputs are: energy and material. Sustainable manufacturing deals with these issues of reducing inputs or making changes in processes or source [3]. In general, electrical energy is one of the most important source to manufacture a product [6]. Electrical energy is converted into useful work and waste in the form of heat. In this regard, concept of energy should be considered [7]. Like every product cycle, manufacturing processes also require energy to convert raw materials into finished product.In LCA (Life Cycle Assessment), amount of energy consumed is the main concern. Energy utilized in manufacturing can be categorized into direct and indirect energy. Direct energy is the energy required to manufacture a product while indirect energy is the energy consumed to maintain the environment in which product is manufactured. Direct energy can be further categorized into theoretical and auxiliary energy. Theoretical energy is the minimum amount of energy required for a process while auxiliary energy is the energy involved in supporting $40 \%$ of $\mathrm{CO}_{2}$ is emitted due to manufacturing. So, eliminating or reducing the carbon emission is the main goal of manufacturers [8].

In manufacturing, machining is one of the most important process. Its role in manufacturing sector and global economy cannot be neglected. However, it produces huge amount of carbon footprints and that is expected to increase by $2 \%$ per year [9]. In general, emission of $\mathrm{CO}_{2}$ is due to electrical energy consumption by a machine tool. The Cooperative effort in process emission $\left(\mathrm{CO}_{2} \mathrm{PE}\right)$ categorized the states of machine tools into two main groups: 'Basic state' and 'Cutting state'. In the basic state, electrical energy is required to start the machine components. In the cutting state, energy is required to remove the material. In between these two states, there is also an intermediate state called 'Ready state'. In this state, more energy is consumed in order to move the spindles. After the machine start-up, the highest power is consumed in the ready state. Energy needed to operate at no load is higher that energy required at the tip of tool [7]. Experiments have shown $[7,8,10]$ that the energy requirement is frequently controlled by the support features of the equipment rather than the actual physical mechanism of the process. Machine tool is the gathering of different components, like drives, pumps, lead screw, fans etc. Energy consumption of machine tool depends on its components. Comparing machine tools in different operating modes, identify energy inefficient components and compare the energetic behaviour of different machine tool components are some common requirements for

Mehran University Research Journal of Engineering \& Technology, Volume 39, No. 1, January, 2020 [p-ISSN: 0254-7821, e-ISSN: 2413-7219] 
capabilities of machine tool energy model [11]. In cutting, rotational speed of main spindle, transitional speed, cutting depth, work piece material, cutting tool and angle set between work piece and machine tool are also important parameters to be considered for energy consumption optimization [12]. However, later is bit difficult to relate.

Electrical energy consumption in mechanical machining (traditional) has been studied in detail as traditional machining has become an important process to save energy and reduce waste [6]. For the greater advantage from the machining process there is a need to find direct electrical energy requirements in non-traditional process too. Wire cut EDM, also called electro-erosion machining [13], is one of the important non-traditional way of cutting material. The process used spark energy that makes it capable of cutting intricate geometry even into the hardest material with unique advantage of long cutting edge, small kerf, less tapper and homogeneous surface with better stability and higher productivity [14]. For the above said advantage it has become an alternative to other nontraditional processes and had achieved a great significance in manufacturing sector. The process requires high power density and high pulse intensity for constant cutting. It is therefore, this process is categorized as high energy disbursed process.

Optimization of direct energy demands is the biggest challenge in manufacturing world. Higher energy consumption produces higher $\mathrm{CO}_{2}$ emission and higher cost of production. It is necessary to minimize the carbon emission in manufacturing processes. It is presumed that non-traditional machining processes consumes large amount of energy and hence effects the environment. This work was intended to find the framework for power requirements in non-traditional machining and to compare electrical energy requirement with traditional machining process. The significance of this research lies in identifying energy requirement of wire-cut EDM that can be helpful to save money, enhance competitive advantage for manufacturer, reduce environmental impacts and improve and/or develop energy consumption models.

\section{METHOD AND MATERIAL}

\subsection{Energy demand for EDM Wire-Cut}

Gutowski et. al.[7] in his research has anticipated a mathematical model to calculate the electrical energy requirement for a manufacturing process. In their research, electrical energy demands were categorized into two groups, Basic state and the cutting state whereas, ready state power was discussed under basic power. With this in line, in this work energy demands were monitored as the events were streamed. Stainless steel (S304), Nickel and chromium alloy was used as a work piece. This material was selected as it is the practical choice for most of the environment.Geometry profile and specifications of the part is shown in Fig. 1.The EDM Wire cut machine was switch on and the power drawn by that machine at different state/event was measured. Table 1provide the details of events. Same events were performed with load and no load condition. This method provides ease to differentiate among different event streamed. The current consumptions were measured with TES-3600N 3P4W Power analyzer.To identify power requirements of the machine accurately, Power logger is connected to main supply terminal of the wire-cut machine and for more precision its set at least count of 2 seconds. So thousands of readings with a periodic interval of 2 seconds were taken to get the smooth graph and clear visualization of happening. Out lair values due to machine jerk and voltage fluctuations were eliminated. The experiment repeated three times on different days at different part of the day. Table 2 shows the sample readings from the power logger.

Mehran University Research Journal of Engineering \& Technology, Volume 39, No. 1, January, 2020 [p-ISSN: 0254-7821, e-ISSN: 2413-7219] 
Fig. 2 shows the average power profile drawn by molybdenum wire-cut TOPSCNC EDM machine, starting from when a machine switch was on. The energy demand is the area under the graph plotted on Power-Time domain. The Graph in Fig. 2 identify four major phases: first phase shows the power drawn when the machine was switched

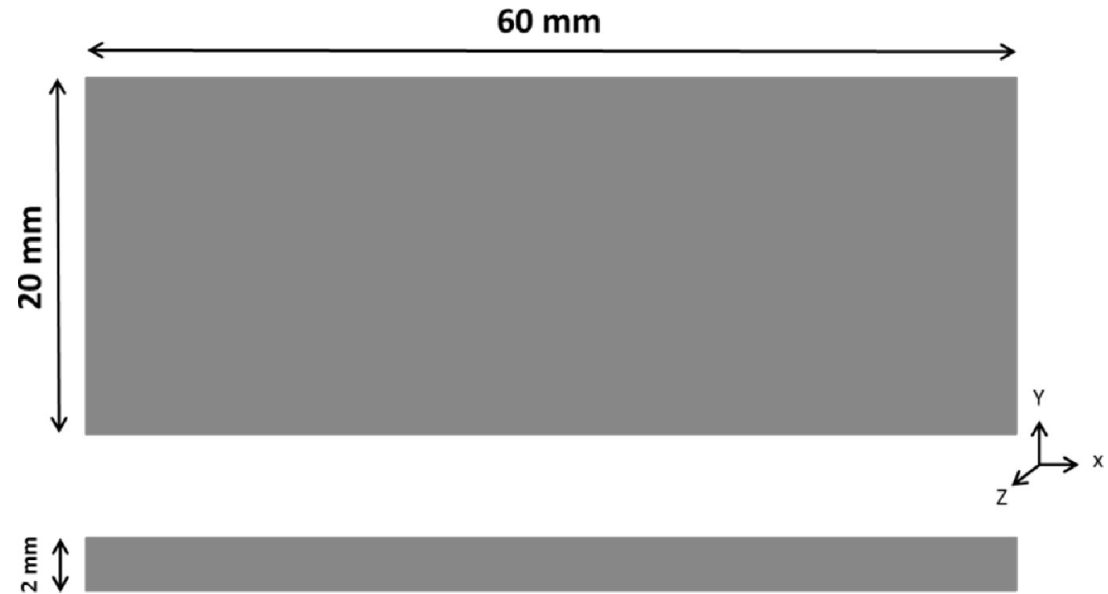

FIG. 1. GEOMETRY AND SPECIFICATION OF WORK-PIECE

TABLE 1. EVENTS STREAMED

\begin{tabular}{|c|c|}
\hline Sequence & Events \\
\hline 1 & Check all connection \\
\hline 2 & Main supply on \\
\hline 3 & Machined switch on \\
\hline 4 & Home position \\
\hline 5 & Coolant (ON/OFF) \\
\hline 6 & Along x axis \\
\hline 7 & Along y axis \\
\hline 8 & Along x-y axis \\
\hline
\end{tabular}

TABLE 2. EXPERIMENT DATA FROM POWER-LOGGER

\begin{tabular}{|c|c|c|c|c|}
\hline $\begin{array}{c}\text { Time } \\
(\mathrm{sec})\end{array}$ & $\begin{array}{c}\text { Voltage } \\
(\text { volts })\end{array}$ & $\begin{array}{c}\text { Current } \\
(\text { amperes })\end{array}$ & $\begin{array}{c}\text { Theta } \\
\text { (radians) }\end{array}$ & $\begin{array}{c}\text { Total Power Supplied } \\
\text { (watts) }\end{array}$ \\
\hline 0 & 221.2 & 0.2 & 1.571 & 44.24 \\
\hline 2 & 220.8 & 0.211 & 1.571 & 46.5888 \\
\hline 4 & 221.4 & 0.201 & 1.571 & 44.5014 \\
\hline 6 & 221.4 & 0.2005 & 1.571 & 44.3907 \\
\hline 8 & 221.1 & 0.201 & 1.571 & 44.4411 \\
\hline 10 & 221.9 & 0.20015 & 1.571 & 44.413285 \\
\hline 12 & 221.6 & 0.2 & 1.571 & 44.32 \\
\hline 14 & 221.3 & 0.211 & 1.571 & 46.6943 \\
\hline 16 & 221.5 & 0.201 & 1.571 & 44.5215 \\
\hline 18 & 221.4 & 0.2005 & 1.571 & 44.3907 \\
\hline 20 & 221.4 & 0.20202 & 44.727228 \\
\hline
\end{tabular}

Mehran University Research Journal of Engineering \& Technology, Volume 39, No. 1, January, 2020 [p-ISSN: 0254-7821, e-ISSN: 2413-7219] 
on and was on standby position. During this phase no machining and no axes movement were carried. On average the power consumed in this phase was 55 Watts. Second phase illustrate the power utilized in moving the axes. It was worth to be noted here that the power required in moving the axes independently or simultaneously draws same power. The sequence of movement performed was as follows; starting from home, first along $\mathrm{x}$-axis then $y$-axis and then $x-y$ axis and lastly set machine to zero position. Total power drawn during this phase was found to be 85 watts. Power consumed in phase two can be treated as ready state power. Third part/phase of the graph is related to actual cutting. Power drawn during this phase was equal to 412 watts. It is worth to mention that during this phase machining was performed dry i.e. without coolant. Finally, in the fourth phase coolant was turned on and machining was performed. A noticeable rise (128 watts) in power consumption was observed for this event. This could be explained as the effect of pump using power to build the pressure of the coolant. On average, basic power of the machine adds up to $40 \%$ whereas cutting power was $60 \%$ of the total power.

\subsection{Different Wire-Cut EDM}

To examine the variability in power consumption of EDM machine system, three different commercial purpose machines were explored (Fig. 3). All three machines were available in Karachi and were from different manufacturers. Table 3 provides the average consumption of electricity used by the machines. It was perceived that power demand for different machines follows the similar trend as presented in Fig. 3. From the measured data it was evident that from the basic power it was the coolant pump that draws the most power. Also, it's the actual machining performed by EDM that consumes major of inputted electricity.

On average, for all three machines the electrical power consumed by different feature of EDM can be illustrated in percentage column of Table 3. However, it is worth to be noted that machines functionality were somewhat different from each other. Therefore, there is a slight difference in power consumptions due machine technology.

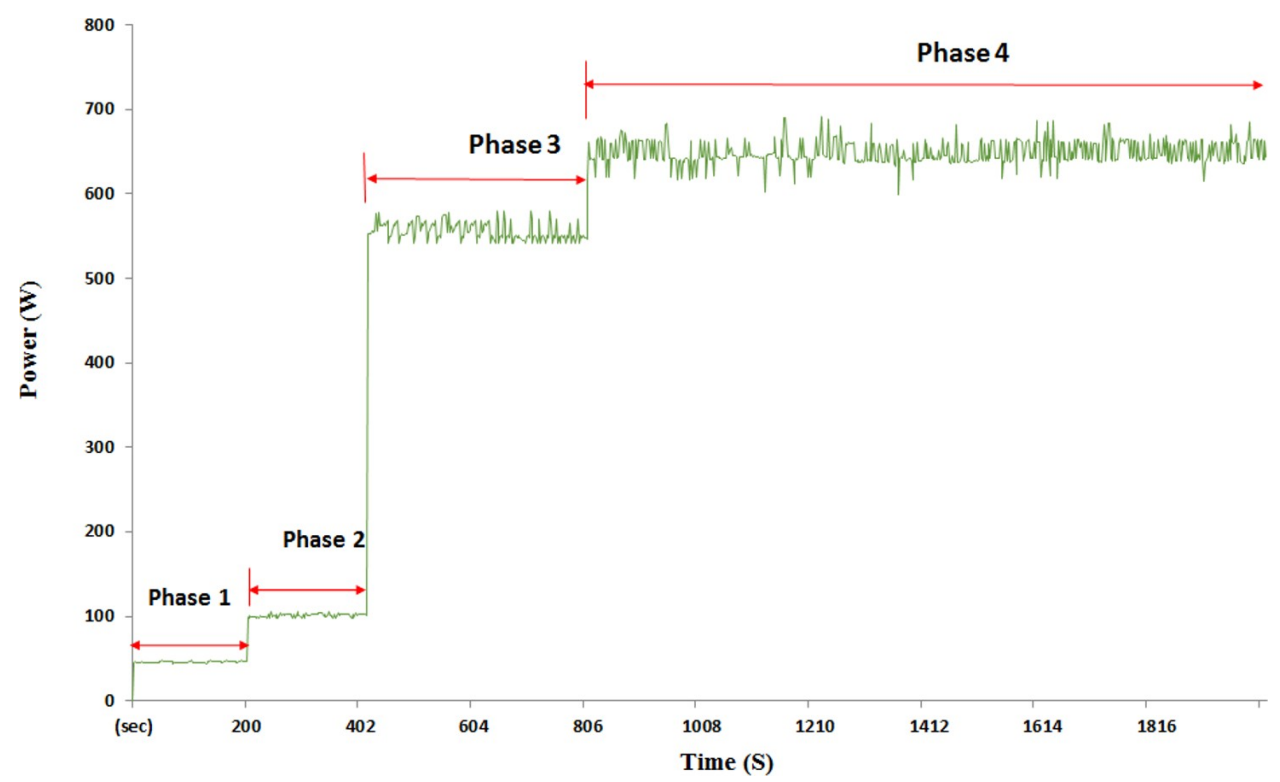

FIG. 2. POWER PROFILE TOPSCNC WIRE-CUT EDM MACHINE

Mehran University Research Journal of Engineering \& Technology, Volume 39, No. 1, January, 2020 [p-ISSN: 0254-7821, e-ISSN: 2413-7219] 


\subsection{Traditional verses Non-Traditional (EDM)}

Traditional machining processes have been widely used in manufacturing industries. They have gained recognition as these processes can create part with cost efficiency. Electrical energy requirement for these processes has been explore by different researchers. Literature review presented by Ampara et. al.[15] discussed the electrical energy consumption in mechanical machining processes. It was evident that non cutting action dominates the power demand in machining processes i.e. constant power demand for start-up and run time. In order to compare the energy demand for traditional process, the same part material and geometry was milled on Denford CNC milling and power requirement was observed. The cutting parameters used for milling are presented in Table 4. Currents profile was measured during machining and was converted in to power. It is shown in Fig.4.

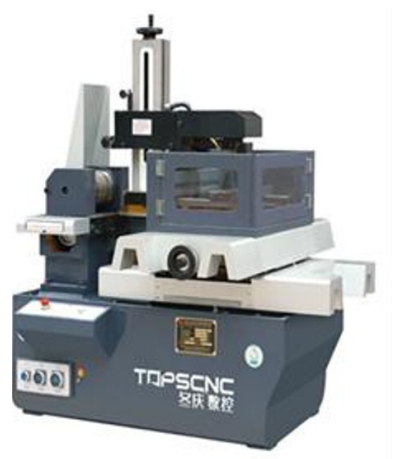

TOPSCNC WIRE-CUT EDM

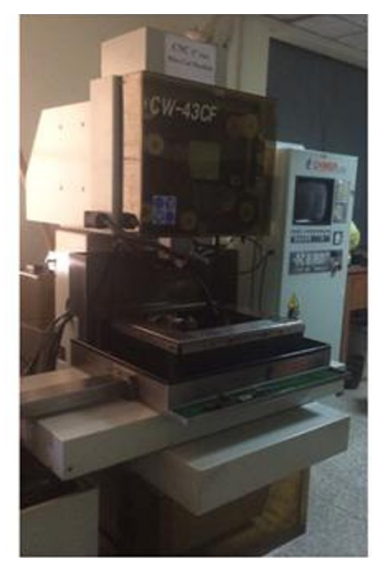

CHMER WIRECUT EDM

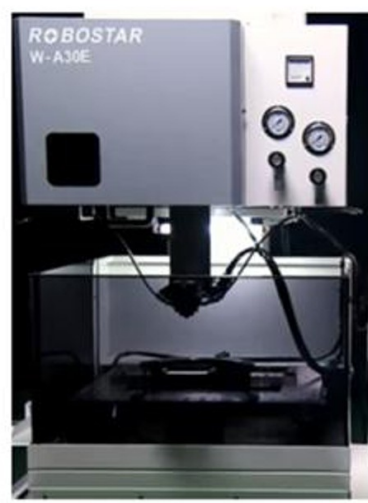

ROBOSTAR WIRECUT EDM

FIGURE 3: DIFFERENT WIRE-CUT EDM MACHINES

TABLE 3. POWER FOR DIFFERENT WIRE-CUT EDM

\begin{tabular}{|c|c|c|c|c|}
\hline \multirow{2}{*}{} & \multicolumn{3}{|c|}{ Power (Watts) } & \multirow{2}{*}{$\begin{array}{c}\text { Percentages Range } \\
\text { (\%) }\end{array}$} \\
\cline { 2 - 5 } & Topscnc & Chmer & Robostar & 100 \\
\hline Total power & 680 & 700 & 687 & $8-12$ \\
\hline Machine Standby & 55 & 84 & 65 & $10-14$ \\
\hline Servo motor & 85 & 70 & 96 & $19-24$ \\
\hline Coolant pump & 128 & 170 & 385 & $53-60$ \\
\hline Machining/cutting & 412 & 376 & 141 & \\
\hline
\end{tabular}

Mehran University Research Journal of Engineering \& Technology, Volume 39, No. 1, January, 2020 [p-ISSN: 0254-7821, e-ISSN: 2413-7219] 
TABLE 4. MACHINING PARAMETERS FOR MILLING PROCESS

\begin{tabular}{|c|c|}
\hline $\begin{array}{c}\text { Spindle Speed } \\
(\mathrm{RPM})\end{array}$ & $\begin{array}{c}6000 \\
(5 \mathrm{~m} / \mathrm{min})\end{array}$ \\
\hline Feed Rate (mm/rev) & 0.20 \\
\hline Depth of Cut (mm) & 0.1 \\
\hline Tool Diameter (mm) & 15 \\
\hline No. of Cutting Edges & 6 \\
\hline
\end{tabular}

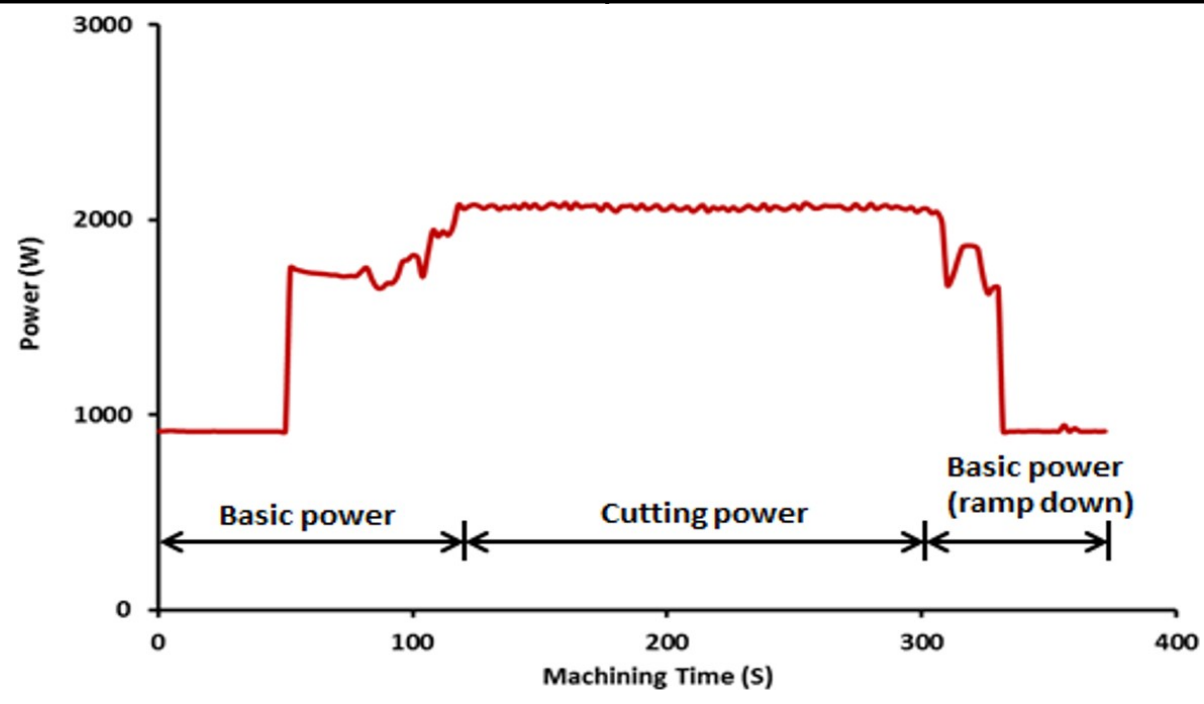

FIG. 4. POWER PROFILE MILLING EXPERIMENT

TABLE 5. POWER DISTRIBUTION FOR MILLING PROCESS

\begin{tabular}{|c|c|c|}
\hline 1 & $\begin{array}{c}\text { Power } \\
\text { (Watts) }\end{array}$ & $(\%)$ \\
\hline Total Power & 2000 & 100 \\
\hline Basic Power & 1760 & 88 \\
\hline Machining & 240 & 12 \\
\hline
\end{tabular}

\section{CONCLUSION}

After considering all the above experimental facts, following conclusion can be deduced form the study.

(i) For energy efficient EDM machine tools, redesigning of the coolant pump to deliver adaptive, intelligent and robust energy efficient controls is essential. This will significantly improve an imperative for sustainable manufacturing.

(ii) From energy models available in literature it is evident that there are three factors - machine tool structures, setup conditions and machining parameters that have impacts on energy consumptions. Results obtained in this research can provide data integration to create a hybrid model by combining the basic energy demands of the EDM machine and energy demand of a value added process. The framework can be model by looking at the value of current and other machining event streaming.

(iii) EDM wire-cut machine tools withdraw 50\% less basic energy, which is the power required to keep the machine in running mode, than conventional CNC machine. While for value adding process (i.e. actual machining/cutting) its draw $40 \%$ more power than that of $\mathrm{CNC}$ milling. This is relatively because of high cycle time and slower 
manufacturing rate of EDM. For resource efficient machining long cycle time is the major challenge in EDM technology while for mechanical machining lowering basic power will have significant impact on energy demand. Including the manufacturing rate in LCA will more accurately capture the impact of these technologies on the environment.

\section{ACKNOWLEDGEMENT}

Authors are thankful to Mr.SaadTanveer and MS BatoolRivi, for preparatory work. Authors also want to show the gratitude to NED University of Engineering \& Technology, Karachi, Pakistan, for using their equipment to conduct experiments.

\section{REFERENCES}

[1] Sorrell, S.,"Reducing Energy Demand: A Review of Issues, Challenges and Approaches", Renewable and SustainableEnergy Reviews, Volume 47, pp. 74-82, [DOI: 10.1016/j.rser.2015.03.002], 2015.

[2] Seow, Y., and Rahimifard, S.A., "Framework for Modelling Energy Consumption within Manufacturing Systems", CIRP Journal of Manufacturing Science and Technology, Volume 4, pp. 258-264, [DOI: 10.1016/ j.cirpj.2011.03.007], 2011.

[3] Weenen, J.C.V.,"Towards Sustainable Product Development", Journal of Cleaner Production, Volume 3, pp. 95-100, [DOI: 10.1016/0959-6526(95)00062J], 1995.

[4] Ali, H.M.K., Sultan, A.,and Rana, B.B.,"Captive Power Plant Selection for Pakistan Cement Industry in Perspective of Current Energy Crises: A Fuzzy-AHP Approach", Mehran University Research Journal of Engineering \&Technology, Volume 4, No. 4, pp. 12- 36, [DOI:10.22581/muet1982.1704.02], Jamshoro, Pakistan, October, 2017.

[5] Narejo, G.B., Azeem, F., and Zardari, S., "An Energy Policy Analysis and Proposed Remedial Actions to Reduce Energy Crises in Pakistan”, Mehran University Research Journal of Engineering \& Technology, Volume 36, No. 2, pp. 401-406, [DOI:10.22581/muet1982.1702.18] Jamshoro, Pakistan, April, 2017.

[6] Zhao, G.Y., Liu, Z.Y., He, Y., Cao, H.J., and Guo, Y.B.,'Energy Consumption in Machining: Classification, Prediction, and Reduction Strategy", Energy, Volume 133, pp. 142-157, [DOI: 10.1016/ j.energy.2017.05.110], 2017.
[7] Gutowski, T., Dahmus, J.,and Thiriez, A., "Electrical Energy Requirements for Manufacturing Processes", 13th International Conference of Life Cycle Engineering,Volume 2 Wim Dewulf Joost R. Duflou, Barbara Willems, Tom Devoldere, (Editors),pp. 623627, Katholieke Universiteit Leuven, Belguim, 2006.

[8] Jeswiet, J.,and Kara, S.,"Carbon Emissions and CES ${ }^{\mathrm{TM}}$ in Manufacturing”, CIRP Annals Manufacturing Technology, Volume 57, pp. 17-20, [DIO: 10.1016/ j.cirp.2008.03.117], 2008.

[9] Jia, S., Yuan, Q., Ren, D.,and Lv, J.,"Energy Demand Modeling Methodology of Key State Transitions of Turning Processes", Energies, Volume 10,[DOI:10.3390/ en10040462], 2017.

[10 Balogun, V.A.,and Mativenga, P.T.,"Modelling of Direct Energy Requirements in Mechanical Machining Processes", Journal of Cleaner Production, Volume 41, pp. 179-186, [DOI:10.1016/j.jclepro.2012.10.015], 2013.

[11] Gontarz, A., Züst, S., Weiss, L., and Wegener, K.,Energetic Machine Tool Modeling Approach for Energy Consumption Prediction", 10th Global Conference on Sustainable Manufacturing, Institute of Machine Tools and Manufacturing, Swiss Federal Institute of Technology, Switzerland, Istanbul,Turkey, 2012.

[12] Duflou, J.R., Sutherland, J.W., Dornfeld, D., Herrmann, C., Jeswiet, J., Kara, S., Hauschild, M.,and Kellens, K.,"Towards Energy and Resource Efficient Manufacturing: A Processes and Systems Approach", CIRP Annals - Manufacturing Technology, Volume 61, pp. 587-609, [DIO: 10.1016/j.cirp.2012.05.002], 2012.

[13] Durairaj, M., Sudharsun, D.,and Swamynathan, N.,"Analysis of Process Parameters in Wire EDM with Stainless Steel Using Single Objective Taguchi Method and Multi Objective Grey Relational Grade", Procedia Engineering, Volume 64, pp. 868-877, [DOI: 10.1016/ j.proeng.2013.09.163], 2013.

[14] Mahapatra, S.S., and Patnaik, A.,"Parametric Optimization of Wire Electrical Discharge Machining (WEDM) Process Using Taguchi Method", Journal of the Brazilian Society of Mechanical Sciences and Engineering, Volume 28, pp. 422-429, 2006.

[15] Aramcharoen, A.,and Mativenga, P.T.,"Critical Factors in Energy Demand Modelling for CNC Milling and Impact of Toolpath Strategy", Journal of Cleaner Production, Volume 78, pp. 63-74, [DOI: 10.1016/ j.jclepro.2014.04.065], 2014. 